\title{
Description of an aerodynamic levitation apparatus with applications in Earth sciences
}

\author{
Andreas Pack*, Katrina Kremer, Nina Albrecht, Klaus Simon, Andreas Kronz
}

\begin{abstract}
Background: In aerodynamic levitation, solids and liquids are floated in a vertical gas stream. In combination with $\mathrm{CO}_{2}$-laser heating, containerless melting at high temperature of oxides and silicates is possible. We apply aerodynamic levitation to bulk rocks in preparation for microchemical analyses, and for evaporation and reduction experiments.

Results: Liquid silicate droplets $(\sim 2 \mathrm{~mm})$ were maintained stable in levitation using a nozzle with a $0.8 \mathrm{~mm}$ bore and an opening angle of $60^{\circ}$. The gas flow was $\sim 250 \mathrm{ml} \mathrm{min}^{-1}$. Rock powders were melted and homogenized for microchemcial analyses. Laser melting produced chemically homogeneous glass spheres. Only highly (e.g. $\mathrm{H}_{2} \mathrm{O}$ ) and moderately volatile components $(\mathrm{Na}, \mathrm{K})$ were partially lost. The composition of evaporated materials was determined by directly combining levitation and inductively coupled plasma mass spectrometry. It is shown that the evaporated material is composed of $\mathrm{Na}>\mathrm{K}>>$ Si. Levitation of metal oxide-rich material in a mixture of $\mathrm{H}_{2}$ and $\mathrm{Ar}$ resulted in the exsolution of liquid metal.

Conclusions: Levitation melting is a rapid technique or for the preparation of bulk rock powders for major, minor and trace element analysis. With exception of moderately volatile elements $\mathrm{Na}$ and $\mathrm{K}$, bulk rock analyses can be performed with an uncertainty of $\pm 5 \%$ relative. The technique has great potential for the quantitative determination of evaporated materials from silicate melts. Reduction of oxides to metal is a means for the extraction and analysis of siderophile elements from silicates and can be used to better understand the origin of chondritic metal.
\end{abstract}

\section{Background}

\section{Aerodynamic levitation}

The term aerodynamic levitation is used for a technique, in which solids or liquids are freely floated on top of a vertical gas stream. With this technique, samples are not in contact with any container material. Therefore, aerodynamic levitation allows the conduction of hightemperature experiments while avoiding problems related to the chemical interaction between sample and container walls (e.g., corrosion of oxide crucibles by silicate melts $[1,2]$, gain or loss of siderophile elements and Fe in Pt crucibles, $[3,4])$.

Oxides and silicates can be heated and melted with a $\mathrm{CO}_{2}$ gas laser [5], a mirror furnace [6], or a solar furnace [7], while they are floating on top of the gas stream. Depending on the supplied energy, temperatures $>3000^{\circ} \mathrm{C}$ can be reached [8].

\footnotetext{
* Correspondence: apack@uni-goettingen.de
Georg-August-Universität, Geowissenschaftliches Zentrum, Goldschmidtstraße

* Correspondence: apack@uni-goettingen.de
Georg-August-Universität, Geowissenschaftliches Zentrum, Goldschmidtstraße 1, D-37077 Göttingen, Germany
}

(c) 2010 Pack et al; licensee BioMed Central Ltd. This is an Open Access article distributed under the terms of the Creative Commons Attribution License (http://creativecommons.org/licenses/by/2.0), which permits unrestricted use, distribution, and reproduction in any medium, provided the original work is properly cited. the physical properties of solids [5] and liquids [9-13] at high temperatures. It has also been used to investigate the crystallization behavior of oxides [14] and silicates [15-17]. Due to the absence of heterogeneous nucleation sites, aerodynamic levitation was also used for the preparation of glasses from substances that otherwise crystallize during cooling [18-20].

In this contribution, we describe an aerodynamic levitation device and demonstrate advantages and limitations of aerodynamic levitation in combination with laser heating for a) sample preparation for bulk rock chemical analyses, b) high-temperature evaporation experiments and c) reduction experiments.

\section{Application fields of aerodynamic levitation in Geosciences \\ Sample preparation for bulk rock chemical analyses}

Bulk rock major, minor and trace element analyses are an integral part of modern geological studies [21]. 
Conventionally, bulk rock analyses are obtained by $\mathrm{X}$-ray fluorescence on fused glass disks, by mass or by optical spectroscopy of dissolved materials, or by instrumental neutron activation analysis. Recently, major, minor and trace element concentrations have been determined on fused bulk rock samples by laser ablation inductively coupled mass spectrometry (LA-ICPMS) [22-26]. Bulk rock glasses were prepared by means of fusion with Li-borate flux in a Pt crucible $[22,25]$ or by melting on an electrically heated Ir strip $[23,27]$. The latter technique requires less material $(<50 \mathrm{mg})$, but results in the loss of some volatile elements from the sample.

Pack et al. [28], Pack [29] and Patzer et al. [30] used aerodynamic levitation in conjunction with $\mathrm{CO}_{2}$ laser melting as preparation technique for analyses of $\mathrm{Ca}, \mathrm{Y}$, REEs, Zr, and Hf in bulk chondrites and achondrites. The analyses were conducted using LA-ICPMS. The concentration of $\mathrm{Ca}$, which was used as internal standard, was determined by electron microprobe analyses (EPMA). Only about $10 \mathrm{mg}$ of sample material was required. In Pack et al. [28], 17 chondrites were analyzed for $\mathrm{Y}$ and Ho at concentration levels of $\sim 2.4 \mu \mathrm{g} \mathrm{g}^{-1}$ and $\sim 0.09 \mu \mathrm{g} \mathrm{g}^{-1}$. Small variations $( \pm 5 \%)$ of the $\mathrm{Y} / \mathrm{Ho}$ ratios were related to fractional condensation processes in the solar nebula. Pack [29] demonstrated that REEs can be determined with a precision better than $\pm 5 \%$ on fused bulk meteorites. It was demonstrated that bulk chondrites do not have unfractionated REE abundances. Patzer et al. [30] showed that precise and accurate bulk rock $\mathrm{Zr} / \mathrm{Hf}$ ratios can be obtained by levitation melting and subsequent LA-ICPMS analysis. Fractionations among refractory lithophile elements were related to processes in the solar nebula 4.6 Ga ago.

Details of the levitation apparatus, however, were not described by Pack et al. [28], Pack [29] and Patzer et al. [30] and will be presented in this contribution. It will also be demonstrated that laser-assisted melting of $\sim 10 \mathrm{mg}$ rock powders is suitable not only for refractory trace element (Y, REE, Zr, Hf), but also for bulk major and minor element analyses.

\section{Evaporation experiments}

Alkali evaporation during chondrule melting Alkalis belong to the group of moderately volatile elements [31]. In cosmochemical context, evaporation of alkalis provides important insights into the conditions (pressure, oxygen fugacity, duration) of chondrule melting in the protoplanetary disk [32,33]. Chondrules are $\sim 0.1$ $1 \mathrm{~mm}$ sized silicate spheres (Fig. 1) that formed by a brief, but intense melting event in the solar nebula [34]. They are major constituents of chondritic meteorites. In a low-pressure ( $10^{-6}$ to $10^{-4}$ bar), $\mathrm{H}_{2}$-rich nebular gas, alkalis are expected to evaporate within minutes from the melt. However, it was shown by Borisov et al. [33] and Alexander et al. [32] that chondrules did not lose alkalis during melting. Melting of chondrules in a noncanonical high-pressure nebular gas [35] may explain the observed absence of alkali evaporation.

We will demonstrate that evaporation of alkalis from levitated molten silicates can be monitored with high time resolution. The applicability of the experimental procedure with respect to the problem of alkali-retentionin chondrules will be discussed.

\section{In-situ reduction of silicate melts}

Chondrites and chondrules contain metal that did not form by direct condensation from the solar nebula. Instead, it has been suggested that metal in chondrites formed by reduction from oxides during the chondrule melting event [36]. Some chondrules contain $\mathrm{Fe}, \mathrm{Ni}$ metal blebs that may have formed by reduction during the brief chondrule melting event (Fig. 1, modified after [37]). In this contribution, we demonstrate that $\mathrm{Fe}, \mathrm{Co}$, $\mathrm{Ni}$ and likely other and more siderophile elements can be transferred from the oxidized form into liquid metal during levitation.

The usability of the technique for the analysis of siderophile trace elements in rocks will also be discussed.

\section{Results}

The aerodynamic levitation apparatus and sample preparation

The levitation device comprised an infrared (IR) $\mathrm{CO}_{2}$ laser heat source, a levitation chamber with levitation nozzle and a levitation gas supply (Fig. 2).

We used a SYNRAD $50 \mathrm{~W} \mathrm{CO}_{2}$ laser $(\lambda=10.4 \mu \mathrm{m})$ as heat source. The laser was focused to a beam diameter of $\sim 1.5-2 \mathrm{~mm}$ by means of a ZnSe lens $(f=125 \mathrm{~mm})$. The laser energy output could continuously be varied between 0 and $95 \%$. The levitation chamber hosted the levitation nozzle. The chamber was used when conducting experiments in controlled atmospheres (e.g., under reducing conditions) were carried out (or the chamber was used during conducting experiments in controlled atmospheres). Two sapphire windows were used for video monitoring and for illumination. The top of the chamber was covered with an IR transparent $\mathrm{ZnSe}$ window. The levitation nozzle had an opening angle of $60^{\circ}$ and a $0.8 \mathrm{~mm}$ bore (Fig. 3). It was made of aluminum. The levitation gas was regulated with a computer-controlled VÖGTLIN redy mass flow controller $\left(0-1000 \mathrm{~mL} \mathrm{~min}^{-1}\right)$.

Aerodynamic levitation experiments required solid, nearly spherical samples as starting material. One way of preparing such a starting sample was to briefly fire the laser (defocused to $\sim 2 \mathrm{~mm}, \sim 1 \mathrm{~s}$ ) directly into a pot with the sample powder. The powder melted and solidified as nearly spherical glassy droplet. The glass beads could be placed upside down, i.e. with the molten surface directed toward the levitation gas stream in the 


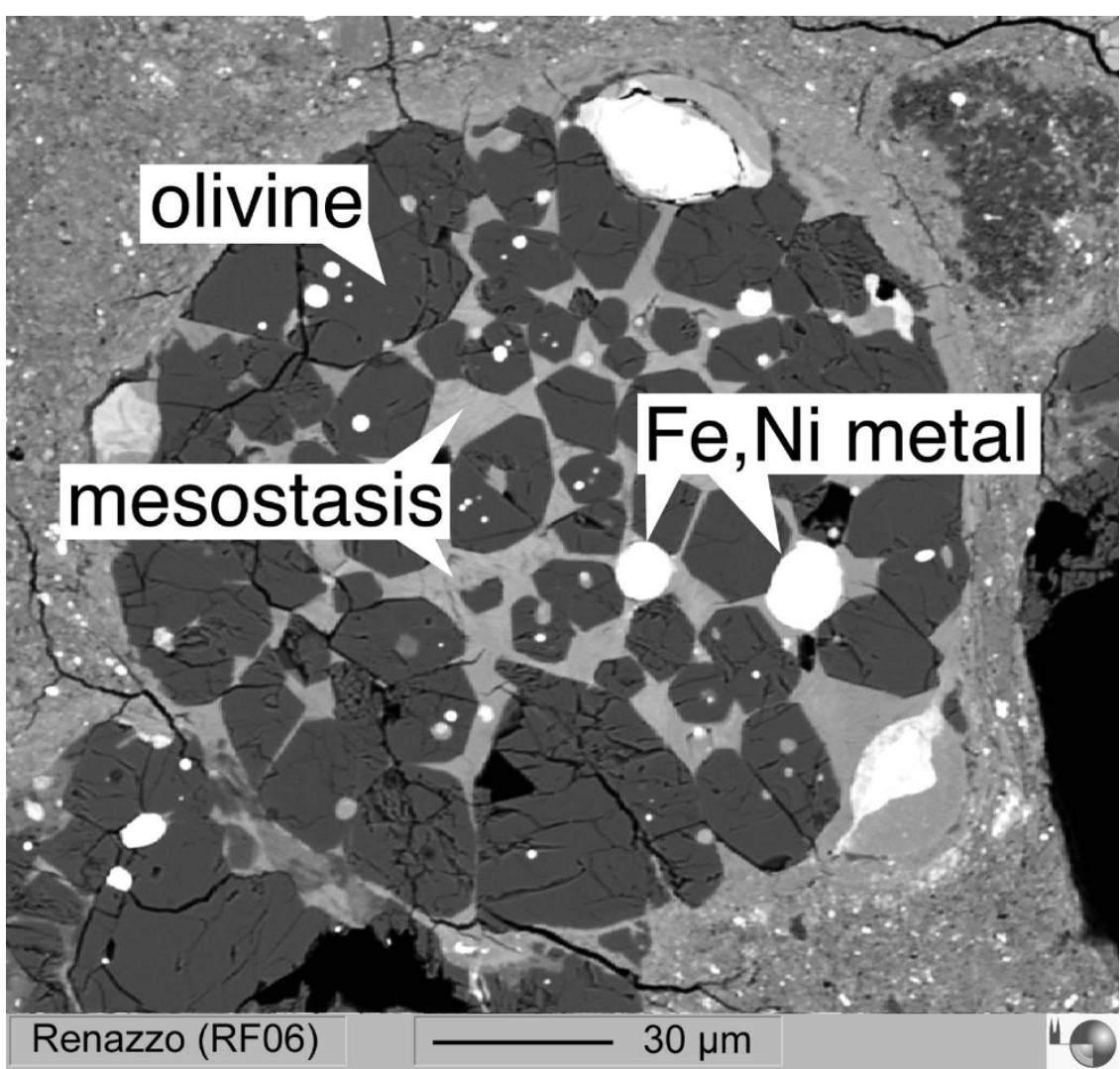

Figure 1 Back scattered electron image of a chondrule from the Renazzo (CR2) carbonacenous chondrite [modified after [37]]. The chondrule contains olivine, metal and intersitial mesostasis.

levitation nozzle. Alternatively, the sample powder $(\sim 10$ $20 \mathrm{mg}$ ) could be placed in a spectroscopy-grade graphite crucible ( $\sim \mathrm{mm}$ inner diameter, $\sim 4 \mathrm{~mm}$ depth) and briefly melted into a glass bead. The resultant bead could be placed in the nozzle for levitation.

Stable levitation was a prerequisite for sample homogenization for chemical analyses as well as for evaporation and reduction experiments. The nozzle with the $60^{\circ}$ opening angle and $0.8 \mathrm{~mm}$ bore allowed to keep molten silicates in a stable position for up to $>1 \mathrm{~h}$ (Fig. 4). We tested also a nozzle with a $0.8 \mathrm{~mm}$ bore, but a wider opening angle of $120^{\circ}$. However, we could not keep the spheres in stable positions with this nozzle. The gas flow was set to $250-300 \mathrm{~mL} \mathrm{~min}^{-1}$ for silicate spheres with $\sim 2 \mathrm{~mm}$ diameter. Smaller as well as larger spheres failed to float stably. The distance between sphere and nozzle was $\sim 1 \mathrm{~mm}$. The aluminum metal nozzle did not reach temperatures exceeding $\sim 100^{\circ} \mathrm{C}$ even in the longrun experiments at full laser power.

\section{Sample preparation for bulk rock chemical analyses}

In order to demonstrate if aerodynamic levitation melting is suitable for major and minor element bulk rock analyses, we prepared glassy spheres of 7 United States
Geological Survey (USGS) standard rock powders: BIR-1 (basalt, 48.0 wt.\% $\mathrm{SiO}_{2}$ ), BHVO-2 (basalt, 49.9 wt.\% $\mathrm{SiO}_{2}$ ), W-2 (diabase, 52.7 wt.\% $\mathrm{SiO}_{2}$ ), BCR-2 (basalt, 54.1 wt.\% $\mathrm{SiO}_{2}$ ), AGV-2 (andesite, $59.3 \mathrm{wt} \% \mathrm{SiO}_{2}$ ), GSP-2 (granodiorite, 66.6 wt.\% $\mathrm{SiO}_{2}$ ), and RGM-1 (rhyolite, 73.4 wt.\% $\mathrm{SiO}_{2}$ ). Bulk compositions (recommended values) from the GeoReM database [38] were taken.

In preparation for levitation, the rock standard powders were pre-fused in small graphite crucibles. A new crucible was machined for each sample in order to avoid any cross contamination. The pre-fused sample beads were placed upside down, i.e. with the glassy surface in the levitation nozzle, levitated and melted between 1 and 4 times for $\sim 5 \mathrm{~s}$ each in an Ar atmosphere (i.e. we used Ar as levitating gas). Argon gas was used because we wanted to avoid changes in oxidation state of the samples. High concentrations of ferric Fe in chondritic samples that were levitated in air led to formation of abundant $<10 \mu \mathrm{m}$ sized quenched spinel crystals [28-30].

The attached video system was used to monitor the fusion process. Remaining crystals were visible as bright spots in the slowly rotating and convecting melts. Only samples with no visible crystals left were used for the 


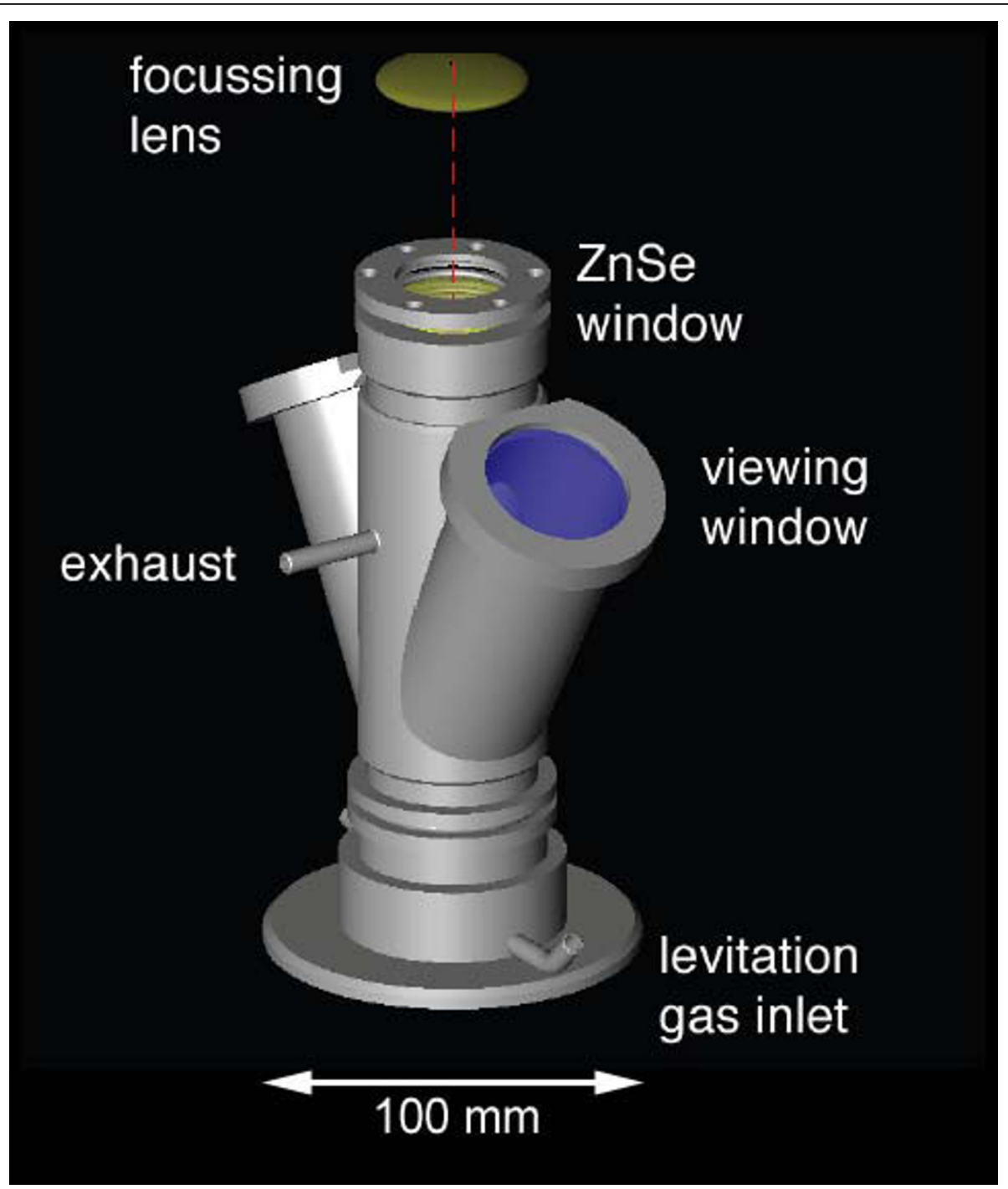

Figure 2 Sketch illustrating the levitation apparatus. The levitation nozzle was placed inside the sample chamber. The chamber comprised sapphire windows for viewing and illumination and a ZnSe window for the laser beam. The levitation gas could be conducted via the exhaust to the source of an ICPMS for chemical analyses.

chemical analyses. The disappearance of crystals indicated that the liquidus temperature was reached. Samples were fused at temperatures only little above their liquidus in order to minimize evaporation.

We quenched the samples by switching off the laser. The cooling rates for aerodynamic levitation experiments with $1 \mathrm{~mm}$ forsterite spheres were reported to be in the range of $700{ }^{\circ} \mathrm{C} \mathrm{s}^{-1}$ [19]. As a result of the high cooling rates and absence of sites for heterogeneous nucleation, all silicate rock standards solidified as glass.

The spheres were removed from the nozzle by means of a pair of tweezers after they cooled down in the Ar gas stream. They were stored in small glass vials. We embedded the glass spheres into resin and prepared polished 1-inch sections. The sections were carbon coated before EPMA. One section contained up to $>40$ spheres.

We used a JEOL 8900R electron microprobe for major and minor element ( $\mathrm{Si}, \mathrm{Ti}, \mathrm{Al}, \mathrm{Mg}, \mathrm{Fe}, \mathrm{Mn}, \mathrm{Na}, \mathrm{K}$; K $\alpha$ lines) chemical analyses of the USGS rock standard glasses. We used a defocused beam $(25 \mu \mathrm{m})$ with acceleration voltage of $15 \mathrm{kV}$ and an electron current of $15 \mathrm{nA}$. The microprobe was calibrated with a set of natural and synthetic silicates and oxides. The calibration was complemented by analyses of reference glasses KL2, GOR128, GOR132, ML3B, T1, StHs6/80 and ATHO [27].

We analyzed 10 randomly selected spots on each of the USGS rock standard glasses. The results of EPMA of the investigated 7 USGS rock standards are listed in Table 1. The internal heterogeneity (major and minor 


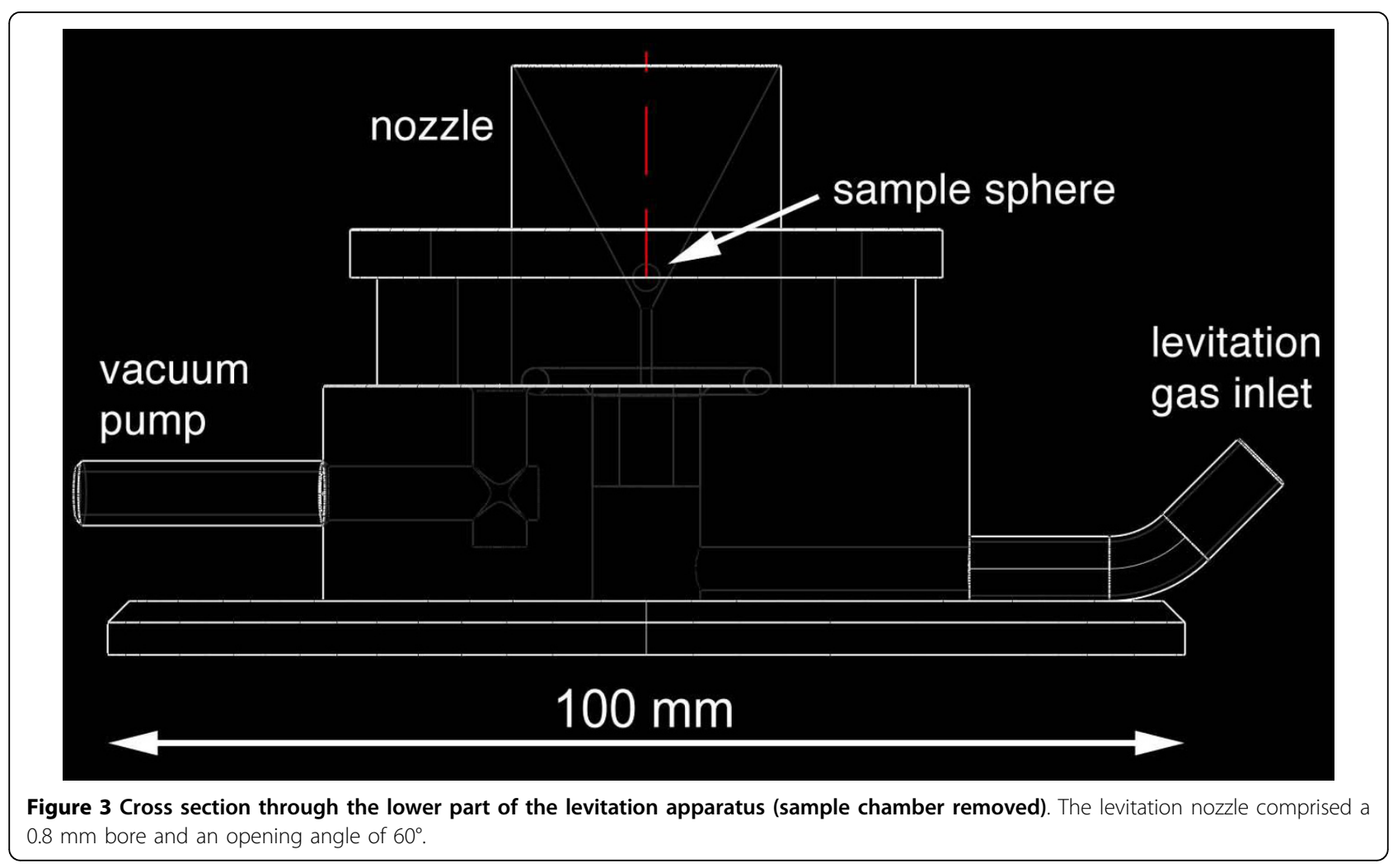

elements, EPMA spots) of the spheres was in all cases $<5 \%(1 \sigma \mathrm{SE}, \mathrm{N}=10)$.

We have displayed all data with normalization on the concentration of the respective reference value of the element and on Al (Figs. 5, 6, 7 and 8). The measured to reference ratios were normalized to $\mathrm{Al}$ because this was the most refractory [i.e. has the highes evaporation temperature; [31,39]] major element in the samples and

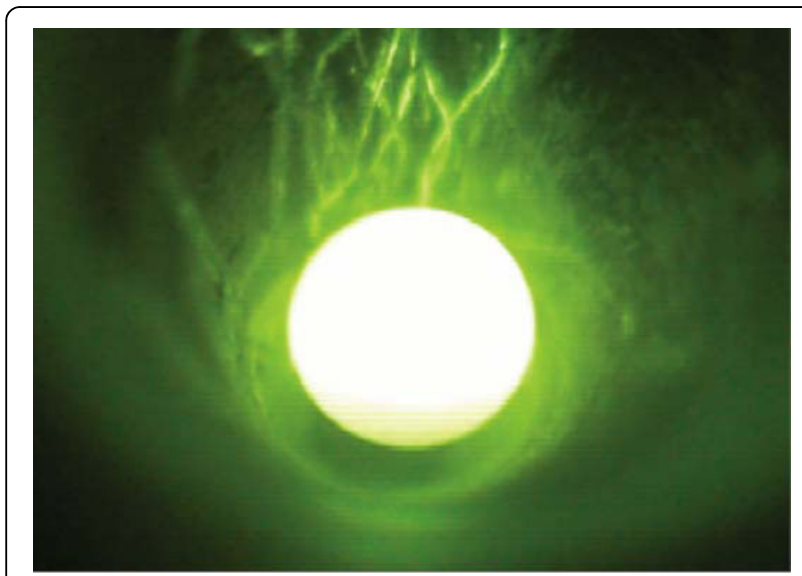

Figure 4 Video image showing a droplet of liquid basalt BCR-2 during levitation. The sample was heated from the top using a $\mathrm{CO}_{2}$-laser. The diameter of the sphere was $\sim 2 \mathrm{~mm}$. was not expected to be lost by evaporation. This is common practice when displaying chemical data with respect to volatility. A ratio of one indicates that the respective element was not lost during melting. A ratio $<1$ indicates evaporation. In such a case, the respective value gives the fraction of the element that remained in the sample. A ratio exceeding unity can only be due to sample heterogeneity.

The refractory element $(\mathrm{Al}, \mathrm{Ti}, \mathrm{Ca}, \mathrm{Mg})$ data from all samples demonstrate that homogeneity increases with the number of fusion steps. A single fusion resulted in significant deviation of e.g., Fe (BIR-1, Fig. 5) or Ti (W-2, Fig. 6) from the normalized reference concentrations. Subsequent fusion steps removed the heterogeneities. Increasing the number of fusion steps, however, also led to increasing loss of moderately volatile elements $\mathrm{Na}$ and $\mathrm{K}$ and, with more intense fusion, also Si and Fe (Figs. 5, 6, 7 and 8).

It is obvious from Figs 5, 6, 7 and 8 that the moderately volatile elements $\mathrm{Na}$ and $\mathrm{K}$ were lost from most samples, even when samples are levitated and fused only once. Exceptions were mafic samples BHVO-2 (Fig. 5) and W-2 (Fig. 6), which showed no loss of $\mathrm{Na}$ and $\mathrm{K}$ when fused once. All samples that were fused between 2 and 4 times show a loss of $20-90 \%$ of $\mathrm{Na}$ and $\mathrm{K}$.

Samples, which have been 2 - 4 times levitation melted showed concentrations of $\mathrm{Al}, \mathrm{Ti}, \mathrm{Ca}$ and $\mathrm{Mg}$ that agreed within $\pm 5 \%$ with the respective reference 
Table 1 Results of EPMA measurements of levitated and fused USGS rock standards

\begin{tabular}{|c|c|c|c|c|c|c|c|c|c|c|c|}
\hline Sample & Times fused & $\mathrm{SiO}_{2}$ & $\mathrm{TiO}_{2}$ & $\mathrm{Al}_{2} \mathrm{O}_{3}$ & $\mathrm{MnO}$ & $\mathrm{Fe}_{2} \mathrm{O}_{3}$ & $\mathrm{MgO}$ & $\mathrm{CaO}$ & $\mathrm{Na}_{2} \mathrm{O}$ & $\mathrm{K}_{2} \mathrm{O}$ & Total \\
\hline \multirow[t]{4}{*}{ BIR-2 } & $1 \times$ & 46.5 & 0.91 & 15.0 & 0.18 & 13.0 & 9.47 & 12.91 & 1.81 & 0.03 & 99.86 \\
\hline & $2 x$ & 47.7 & 0.95 & 15.6 & 0.17 & 11.3 & 9.62 & 13.10 & 1.48 & 0.02 & 99.94 \\
\hline & $3 x$ & 47.5 & 0.95 & 15.8 & 0.18 & 11.1 & 9.69 & 13.23 & 1.09 & 0.02 & 99.63 \\
\hline & $4 \times$ & 47.4 & 0.95 & 16.0 & 0.17 & 11.2 & 9.93 & 13.47 & 0.57 & 0.02 & 99.69 \\
\hline \multirow[t]{4}{*}{ BHVO-2 } & $1 \times$ & 49.6 & 2.68 & 13.5 & 0.17 & 12.2 & 7.25 & 11.09 & 2.16 & 0.48 & 99.16 \\
\hline & $2 x$ & 49.7 & 2.69 & 13.8 & 0.16 & 12.3 & 7.23 & 11.27 & 1.81 & 0.41 & 99.25 \\
\hline & $3 x$ & 49.7 & 2.82 & 14.2 & 0.18 & 12.2 & 7.42 & 11.59 & 1.22 & 0.27 & 99.63 \\
\hline & $4 \times$ & 49.7 & 2.86 & 14.3 & 0.18 & 12.3 & 7.50 & 11.73 & 1.09 & 0.25 & 99.93 \\
\hline \multirow[t]{4}{*}{ AGV-2 } & $1 \times$ & 60.0 & 1.04 & 17.9 & 0.11 & 6.8 & 1.84 & 5.31 & 3.36 & 2.44 & 98.82 \\
\hline & $2 x$ & 59.7 & 1.07 & 18.4 & 0.10 & 6.7 & 1.86 & 5.40 & 3.19 & 2.22 & 98.74 \\
\hline & $3 x$ & 60.4 & 1.09 & 18.8 & 0.10 & 6.7 & 1.90 & 5.48 & 2.86 & 2.10 & 99.40 \\
\hline & $4 x$ & 57.4 & 1.25 & 21.7 & 0.11 & 7.1 & 2.21 & 6.25 & 1.79 & 1.42 & 99.18 \\
\hline \multirow[t]{4}{*}{ BCR-2 } & $1 \times$ & 54.7 & 2.30 & 13.9 & 0.18 & 13.6 & 3.65 & 7.12 & 2.54 & 1.41 & 99.36 \\
\hline & $2 x$ & 54.9 & 2.30 & 14.2 & 0.19 & 13.8 & 3.67 & 7.30 & 2.10 & 1.31 & 99.72 \\
\hline & $3 x$ & 54.1 & 2.50 & 15.2 & 0.23 & 14.1 & 4.01 & 7.87 & 1.02 & 0.72 & 99.80 \\
\hline & $4 x$ & 51.3 & 2.76 & 17.1 & 0.24 & 14.5 & 4.49 & 8.80 & 0.40 & 0.31 & 99.85 \\
\hline \multirow[t]{4}{*}{ W-2 } & $1 \times$ & 52.1 & 0.88 & 15.5 & 0.16 & 10.8 & 6.71 & 10.90 & 2.22 & 0.58 & 99.77 \\
\hline & $2 x$ & 52.0 & 1.03 & 16.2 & 0.16 & 10.8 & 6.52 & 11.10 & 1.63 & 0.47 & 99.81 \\
\hline & $3 x$ & 51.4 & 1.10 & 16.3 & 0.17 & 10.8 & 6.71 & 11.21 & 1.59 & 0.41 & 99.69 \\
\hline & $4 x$ & 51.4 & 1.14 & 16.6 & 0.16 & 10.9 & 6.78 & 11.40 & 1.12 & 0.31 & 99.81 \\
\hline \multirow[t]{4}{*}{ GSP-2 } & $1 \times$ & 66.0 & 0.76 & 17.7 & 0.04 & 4.6 & 1.10 & 2.45 & 1.65 & 3.76 & 98.02 \\
\hline & $2 x$ & 63.2 & 0.87 & 20.3 & 0.05 & 4.8 & 1.23 & 2.67 & 1.49 & 3.50 & 98.03 \\
\hline & $3 x$ & 62.7 & 0.92 & 20.7 & 0.06 & 4.7 & 1.26 & 2.79 & 1.42 & 3.28 & 97.87 \\
\hline & $4 x$ & 62.8 & 0.91 & 21.5 & 0.04 & 4.8 & 1.30 & 2.84 & 1.02 & 2.89 & 98.08 \\
\hline \multirow[t]{4}{*}{ RGM-1 } & $1 \times$ & 73.0 & 0.28 & 14.6 & 0.04 & 1.9 & 0.28 & 1.25 & 3.55 & 4.05 & 98.94 \\
\hline & $2 x$ & 71.9 & 0.31 & 15.8 & 0.05 & 1.9 & 0.33 & 1.38 & 2.86 & 3.62 & 98.12 \\
\hline & $3 x$ & 69.7 & 0.35 & 18.5 & 0.05 & 2.0 & 0.34 & 1.58 & 2.54 & 3.32 & 98.39 \\
\hline & $4 \times$ & 67.9 & 0.36 & 20.4 & 0.05 & 2.2 & 0.40 & 1.77 & 2.33 & 3.23 & 98.61 \\
\hline
\end{tabular}

The samples were fused between once and 4 times $(1 x-4 x)$. All data are given in wt.\% of the oxides.

values. Manganese, Fe and Si also agreed within $\pm 5 \%$ with the reference values, if samples were not fused more than 3 times. Four times of melting led to loss of alkalis, but also of up to $40 \%$ of $\mathrm{Si}$ from the felsic sample RGM-1 (Fig. 8). Loss of Mn, Fe and Si was less severe in the $\mathrm{SiO}_{2}$-poor, mafic materials.

Loss of $\mathrm{Na}$ and $\mathrm{K}$ was clearly related to the number of fusion steps (Fig. 9). The loss of $\mathrm{K}$ correlated with the loss of $\mathrm{Na}$ in all, except the most $\mathrm{SiO}_{2}$-rich samples. In the most $\mathrm{SiO}_{2}$-rich samples GSP-2 and RGM-1 the relative loss of $\mathrm{Na}$ was systematically higher than the loss of K (Fig. 9).

\section{Alkali evaporation experiments}

Alkali (Na, K) evaporation experiments were conducted with a picritic basalt PB-63. The chemical composition of PB-63 was previously determined by X-ray fluorescence (XRF, Göttingen, Table 2). The liquidus temperature was $1620{ }^{\circ} \mathrm{C}$. The picrite was pre-fused to a sphere in a graphite crucible before it was placed in the levitation nozzle. We used the closed sample chamber with
Ar as levitation gas. The outlet of the levitation apparatus was directly connected to the source of an ICPMS in order to monitor the composition of the evaporated material (Fig. 10). The sample was heated and fused with variable laser energy. We monitored the stability of the sphere using the video system.

The intensities of ${ }^{23} \mathrm{Na},{ }^{24} \mathrm{Mg},{ }^{27} \mathrm{Al},{ }^{29} \mathrm{Si},{ }^{39} \mathrm{~K},{ }^{43} \mathrm{Ca}$, ${ }^{55} \mathrm{Mn}$ and ${ }^{57} \mathrm{Fe}$ were continuously monitored with using a PERKIN ELMER DRC II quadrupole mass spectrometer. Dwell times of the isotopes were matched to achieve approximately the same intensities to minimize counting errors especially when determining element ratios.

The relative sensitivity factors $\left(\mathrm{RSF}_{\mathrm{i}}\right)$ for an isotope $j$ of element $\mathrm{i}$ were calculated according to:

$$
R S F_{i}=\frac{C_{i}}{C_{N a}} \times \frac{I^{23} \mathrm{Na}}{I_{j_{i}}}
$$

The RSF values were determined by analyzing the aerosol that was released from the NIST 610 standard 

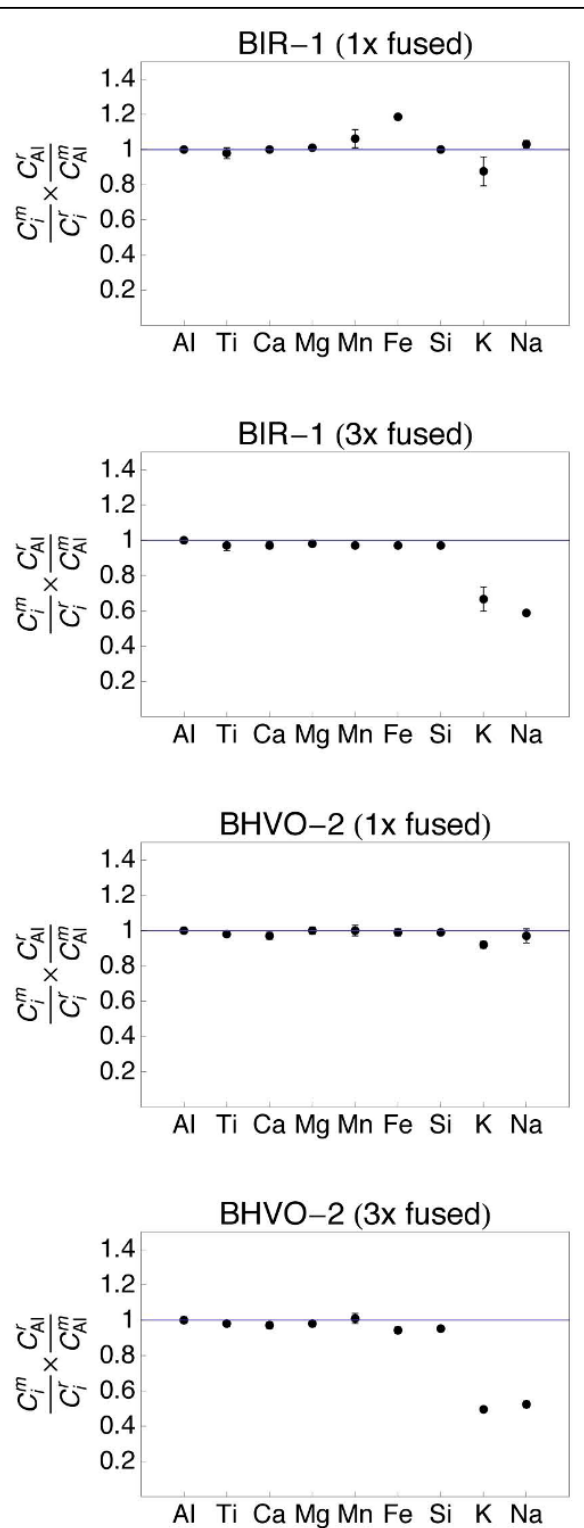

BIR-1 (2x fused)

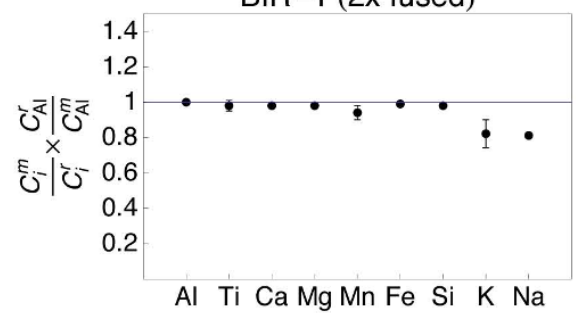

BIR-1 (4x fused)

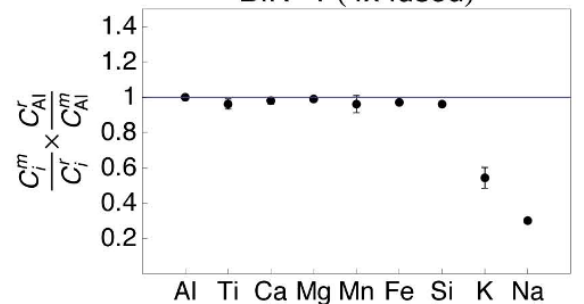

BHVO-2 (2x fused)

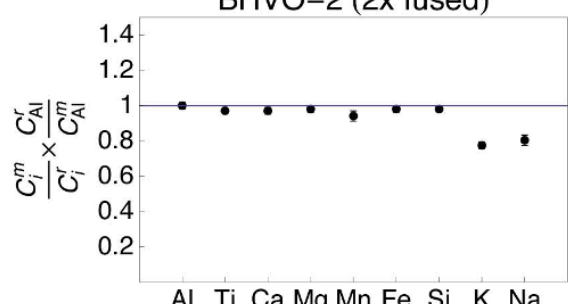

Al Ti Ca Mg Mn Fe Si K Na

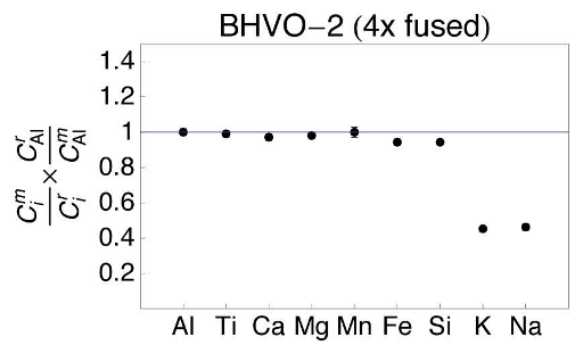

Figure 5 Plots showing the major and minor element composition of quenched spheres (1 - 4 times fused) of basaltic standards BIR-1 and BHVO-2. The element concentrations were normalized to the reference concentrations [38] and to Al (see text for details). The $1 \sigma$ error bars are outlined.

glass during ultra violet (UV, $\lambda=193 \mathrm{~nm}$ ) excimer laser ablation (Table 3 ). In order to average out daily variations, we have adopted the mean RSF values that were obtained over a period of 8 month. Since aerosol from the UV laser ablation and from evaporation experiments will not necessarily have the same properties, concentration data from this study have a larger intrinsic error. It was, however, the purpose of this experiment to demonstrate a possible application of aerodynamic levitation rather than determining the exact composition of the evaporated material.
We used $\mathrm{Na}$ as internal standard because we expected that the Na signal exceeded the signals of other elements in the evaporated aerosol. Sodium was the most volatile of the investigated elements [39]. The relative $1 \sigma$ standard errors of the mean RSF values ranged from 2 to $27 \%$ with an average relative $1 \sigma$ standard error of $\pm 10 \%$.

The concentration $C_{\mathrm{i}}$ of element $i$ in the aerosol was calculated by means of:

$$
C_{i}=R S F_{i} \times \frac{I_{j i}}{I_{23} \mathrm{Na}} \times C_{\mathrm{Na}}
$$



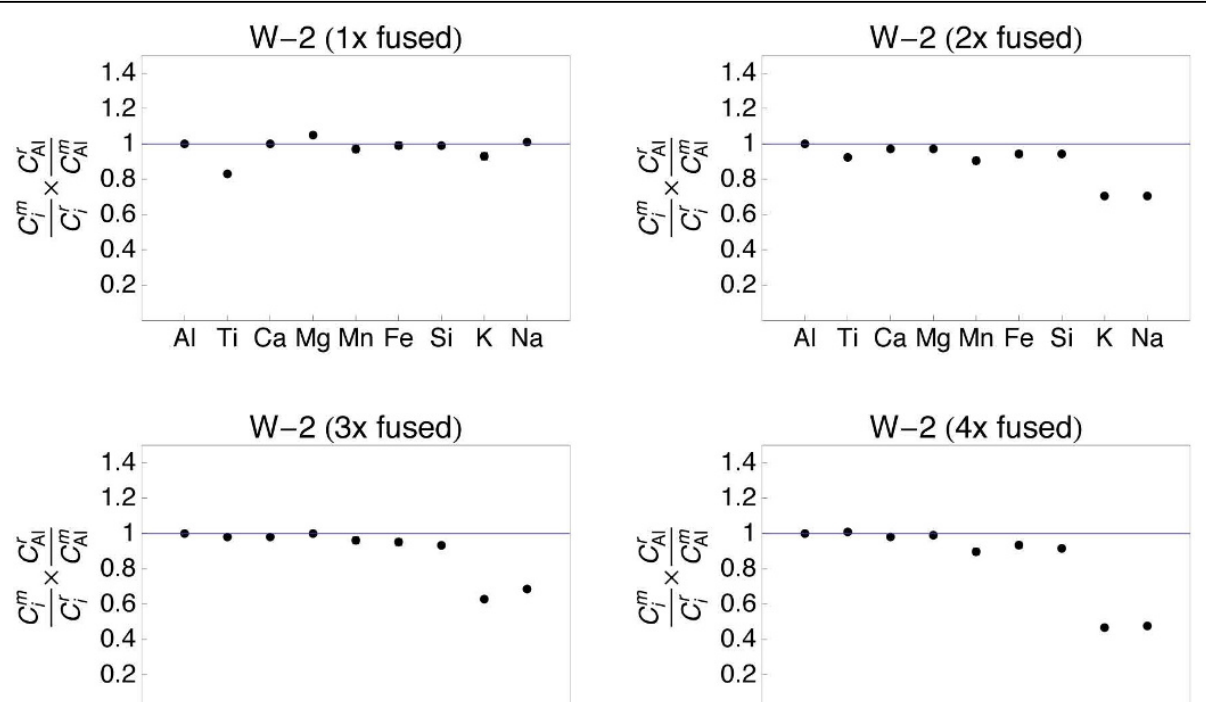

Al Ti Ca Mg Mn Fe Si K Na

Al $\mathrm{Ti} \mathrm{Ca} M \mathrm{Mg} \mathrm{Me} \mathrm{Si} \mathrm{K} \mathrm{Na}$
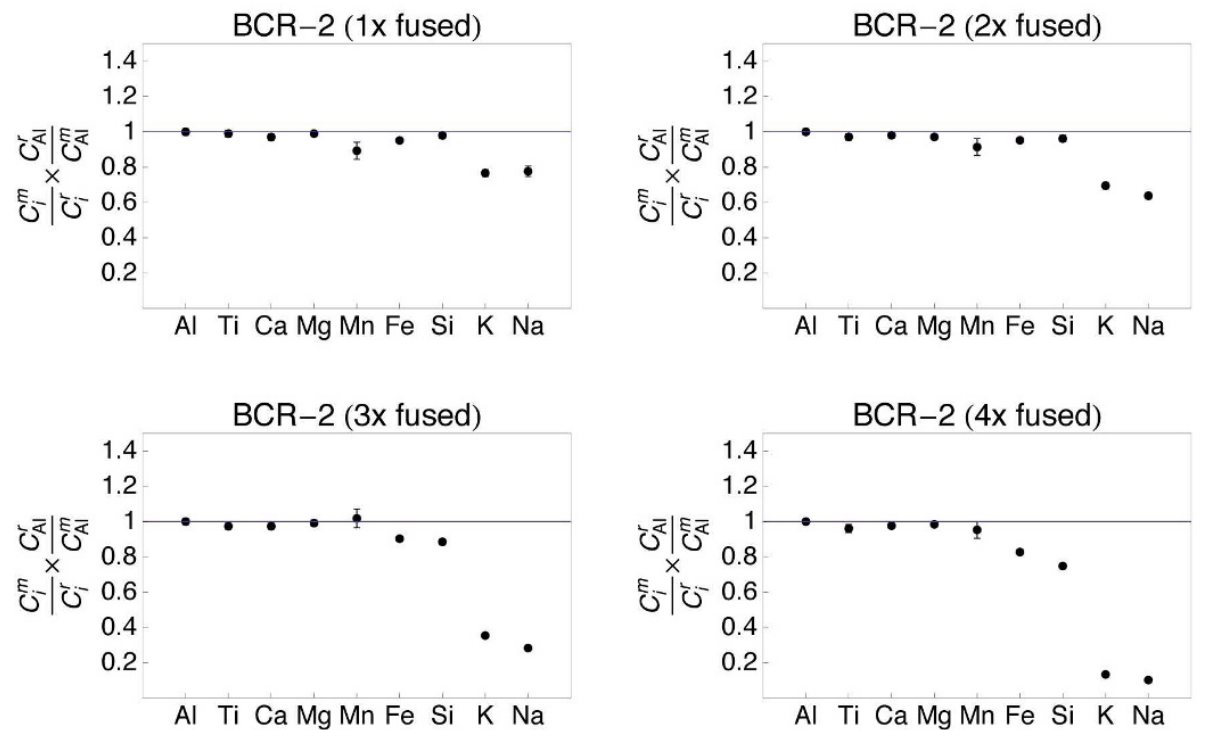

Figure 6 Plots showing the major and minor element composition of quenched spheres (1 - 4 times fused) of standards W-2 and BCR-2 The element concentrations were normalized to the reference concentrations [38] and to Al (see text for details). The $1 \sigma$ error bars are outlined.

Equation 2 shows that the determination of $C_{i}$ requires knowing the concentration of the internal standard (i.e. $\mathrm{Na}$ ). This was, a priori, not known for the aerosol that forms from the evaporated material. Except for oxygen, however, we monitored all major and minor elements $(\mathrm{Na}, \mathrm{Mg}, \mathrm{Al}, \mathrm{Si}, \mathrm{K}, \mathrm{Ca}, \mathrm{Mn}, \mathrm{Fe}$ ) that were present in the evaporated picrite PB-63 (Table 2) and assumed that the sum of the elements in the aerosol amounted $100 \mathrm{wt} . \%$.

$$
\sum C_{i}=100 \text { wt. } \%
$$

Combining Eq. 2 and Eq. 3 thus allowed determination of the composition of the aerosol without knowledge of the concentration of the internal standard element $\mathrm{Na}$. This way, we acquired quantitative analyses of the evaporated material from the picrite $\mathrm{PB}-63$ with high time resolution.

During the evaporation experiment, we heated the picrite PB-63 with laser energies between 20 and $50 \mathrm{~W}$ (Fig. 11). The sample was entirely molten during the whole experiment. The duration of the experiment was $\sim 17$ min. Evaporation started at $20 \mathrm{~W}$ laser energy, but became pronounced at $30 \mathrm{~W}$ (Fig. 11). The total signal increased with increasing laser energy and hence temperature of the melt (Fig. 11). The response time of the system with respect to an increase in laser energy was $\sim 10 \mathrm{~s}$. 

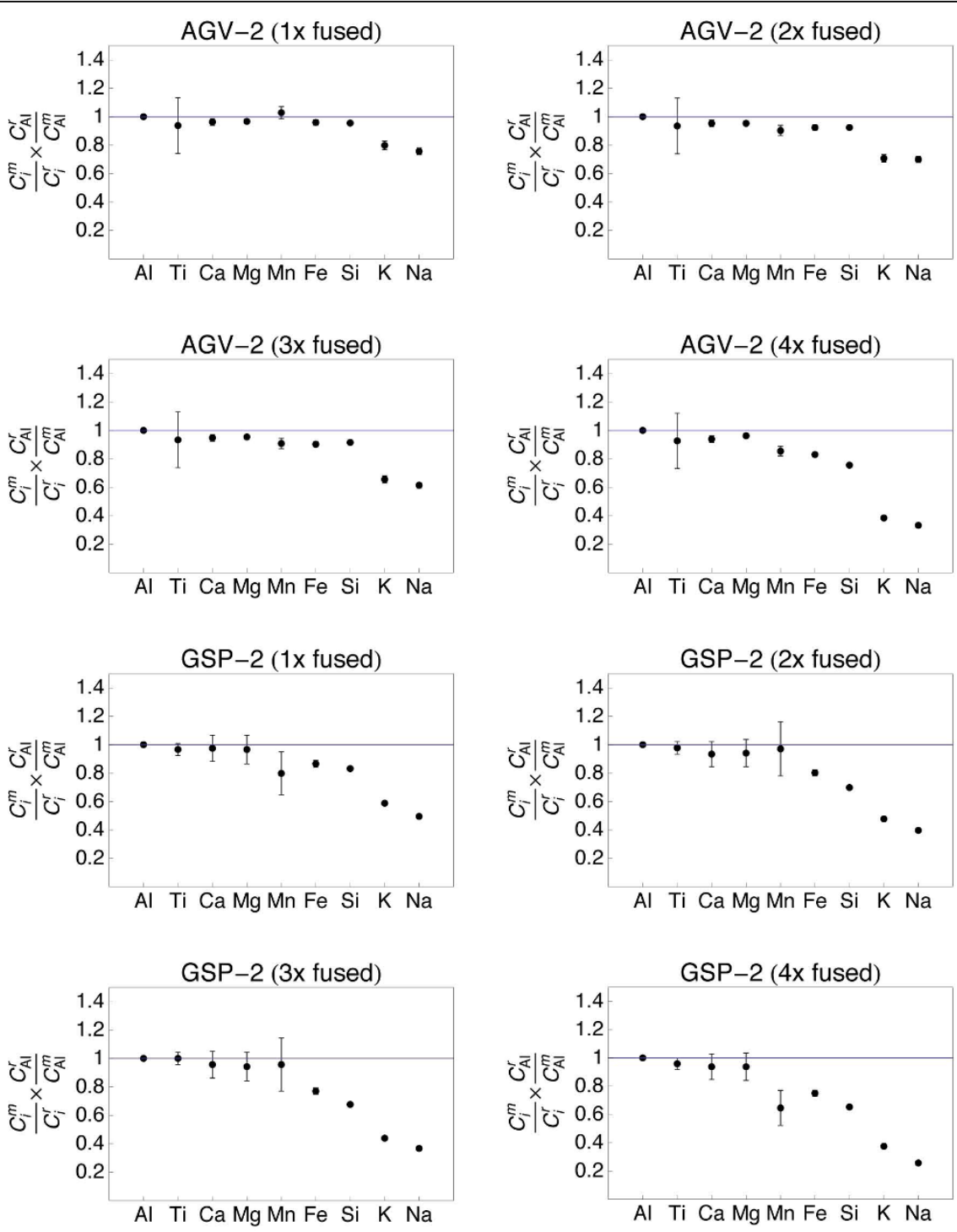

Figure 7 Plots showing the major and minor element composition of quenched spheres (1 - 4 times fused) of andesite AGV-2 and granitoid GSP-2. The element concentrations were normalized to the reference concentrations [38] and to Al (see text for details). The $1 \sigma$ error bars are outlined.

The signal exponentially decayed after switching off the laser with a half live of $\sim 50 \mathrm{~s}$ (Fig. 11).

More than 80 wt.\% of the aerosol was $\mathrm{Na}$ and K (Fig. 12). Both elements showed a strong correlation in the evaporated material. The $\mathrm{Na} / \mathrm{K}$-mass ratio in the evaporated material was in the range between 0.9 and 1.2. The amount of $\mathrm{Si}$ in the evaporated material varied between $\sim 5$ and $\sim 18$ wt.\%. The Si-content increased with increasing temperature. Minor components in the evaporated material were $\mathrm{Mg}$ and Fe; both occurring in the 1 wt.\% concentration level at the highest temperatures (Fig. 13). Other elements were only present as trace components in the evaporated material.

\section{Reduction experiments}

The first reduction experiment was conducted with a mixture of natural spinel lherzolite powder (GZG1275/1, Table 2) that was mixed with 39 wt.\% metal powder $(88.6$ wt.\% Fe, 0.35 wt.\% Co, 10.1 wt.\% Ni). The metal mixture was prepared from analytical grade pure $\mathrm{Fe}, \mathrm{Co}$ and $\mathrm{Ni}$ powders. The spinel lherzolite sample was provided by $\mathrm{R}$. Schoenberg (Hannover) and was identical to the sample analyzed by Schoenberg et al., 2006 [40]. We have determined the chemical composition of the lherzolite by EPMA on a glassy sample that was homogenized by means of levitation melting (Table 2), results are identical within uncertainty. The liquidus temperature of the 


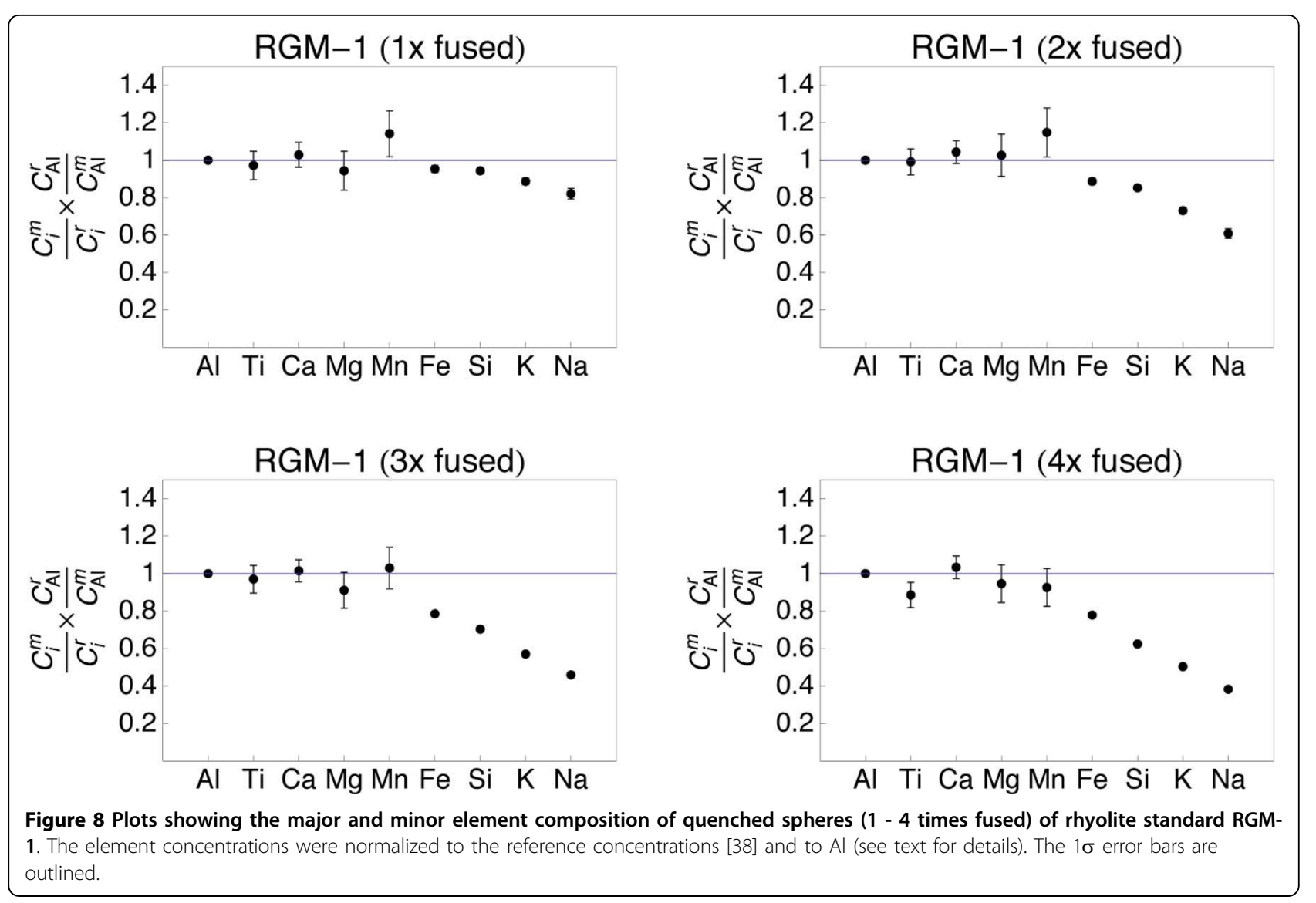

lherzolite was computed with MELTS $[41,42]$ at $1655^{\circ} \mathrm{C}$. The lherzolite metal mixture was oxidized in a muffle furnace $\left(\sim 1000^{\circ} \mathrm{C}, \sim 3 \mathrm{~h}\right)$ in air before melting and levitation in order to transfer the metal to oxides. The change in color of the powder from dark gray towards reddish brown suggested that metal was oxidized. The oxidized powder was re-ground and analyzed by means of X-ray powder diffraction using a Phillips PW 1710 with $\mathrm{Cu}-\mathrm{K} \alpha$ radiation $\left(5^{\circ}<2 \Theta<70^{\circ}, 0.02^{\circ}\right.$ steps, $\left.0.5 \mathrm{~s} \mathrm{step}^{-1}\right)$. No Fe and $\mathrm{Ni}$ metal peaks were identified in the diffraction pattern. Instead, hematite $\left(\mathrm{Fe}_{2} \mathrm{O}_{3}\right)$ and bunsenite $(\mathrm{NiO})$ and olivine were the predominant phases in the pattern.

The liquidus temperature of the oxidized lherzolite metal mixture (see Table 2 for chemical composition) was determined with using MELTS [42] to be $1240^{\circ} \mathrm{C}$ with $\mathrm{FeO}$-rich olivine as liquidus phase.

The starting material was fused in a graphite crucible to a small sphere. The sphere was placed in the nozzle in the closed sample chamber in order to maintain a reducing atmosphere. The levitation gas was a commercially available mixture of 98 vol.\% Ar and 2 vol.\% $\mathrm{H}_{2}$ for $\sim 10 \mathrm{~min}$. The oxide-lherzolite mixture was levitated and melted for about $5 \mathrm{~min}$ in the reducing gas atmosphere. The experimental run product consisted of a silicate fraction and metal (Fig. 14). The metal sphere pointed towards the bottom of the levitation nozzle during melting. Both phases were liquid during the course of the experiment. The surface of the silicate sphere shows marks of skeletal olivine crystals that formed during quenching.

For the second reduction experiment, we used material of the NWA 869 L4-6 ordinary chondrite [43]. The chondrite powder was oxidized in air for $\sim 24 \mathrm{~h}$ in order to transfer all metal into oxides. The sample was reground to powder in a hand mortar after oxidation. No metal grains were left. The sample was briefly pre-fused in a graphite crucible in air. The glass bead was then transferred into the levitation nozzle, where it was levitated using the 98 vol. $\% \mathrm{Ar}+2 \mathrm{vol} \% \mathrm{H}_{2}$ gas mixture. The sample was fused for about $30 \mathrm{~s}$ in the reducing atmosphere and quenched by switching off the laser. It was embedded into resin for electron back scattered electron imaging and EPMA.

The run product consisted of quenched olivine crystals, interstitial glass and round metal droplets (Fig. 15). The composition of the silicate portion was determined by 10 randomly selected EPMA spots $(10 \mu \mathrm{m}$ spot diameter, Table 4). The $\mathrm{FeO} / \mathrm{SiO}_{2}$ mass ratio of the silicate portion was 0.67 . The $\mathrm{NiO} / \mathrm{SiO}_{2}$ ratio of the silicate portion was 0.004 . The metal blebs were rich in $\mathrm{Ni}$ with $\mathrm{Ni}$ 


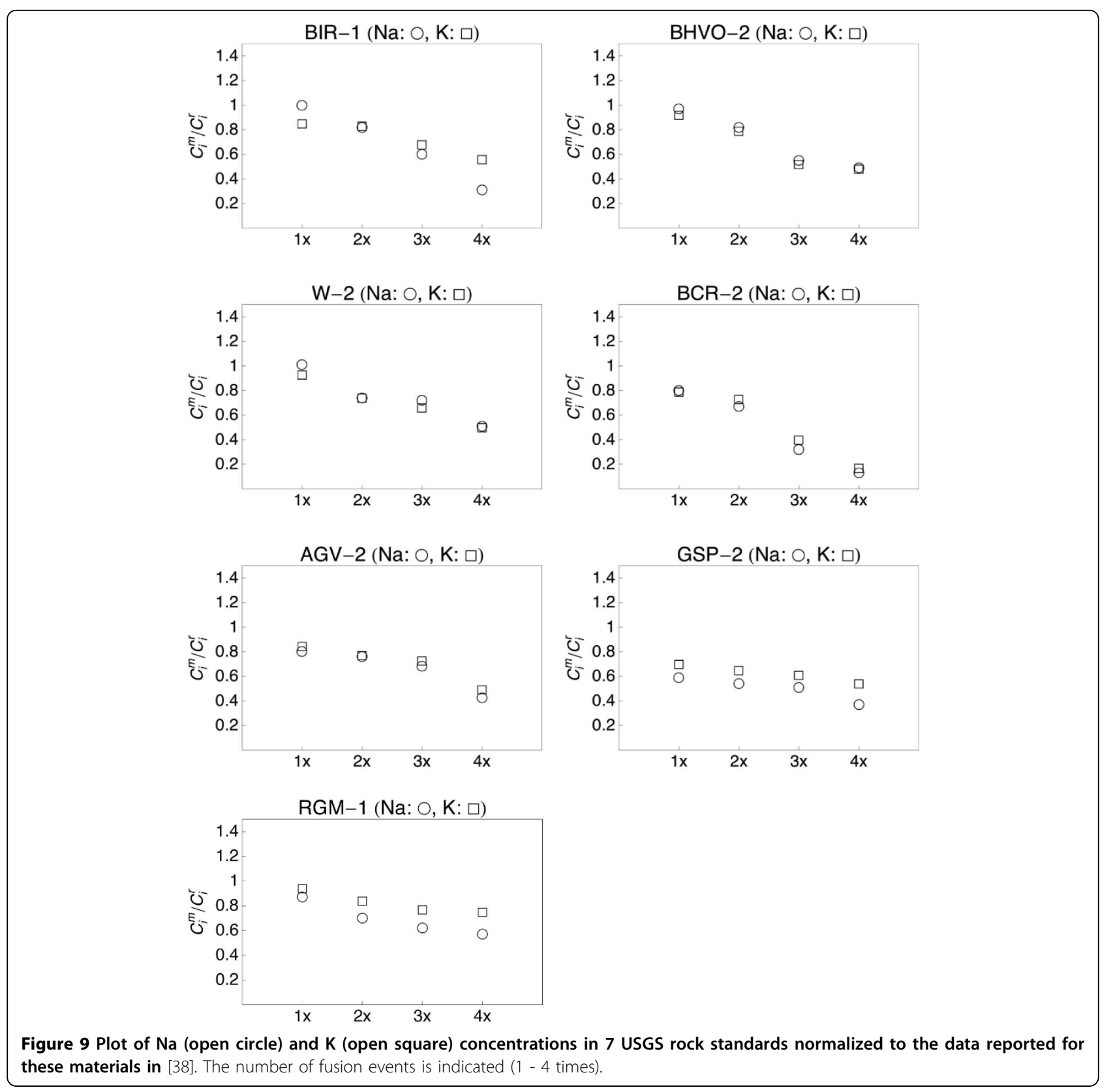

contents between 29.5 and 59.8 wt.\%. The concentration of $\mathrm{Co}$ was negatively correlated with $\mathrm{Ni}$ and varied between 0.69 and 1.38 wt.\%. The concentrations of $\mathrm{Si}$ were $<0.05$ wt.\% in all metal blebs. The mean metal composition is listed in Table 4.

\section{Discussion}

\section{Bulk rock chemical analyses}

The sample preparation protocol was time efficient $(\sim 5$ min per sample) and required only $10 \mathrm{mg}$ of sample powder. Testing different melting durations (Figs. 5, 6, 7 and 8) showed that $2-3$ brief fusion steps ( $~ 5 \mathrm{~s}$ each) were the best compromise between sample homogeneity and loss of elements through evaporation. Non-volatile major and minor elements $\mathrm{Si}, \mathrm{Ti}, \mathrm{Al}, \mathrm{Ca}, \mathrm{Mn}$ and $\mathrm{Fe}$ could be determined with an uncertainty $<5 \%$ relative (Table 2). Moderately volatile elements $\mathrm{Na}$ and $\mathrm{K}$ could not be determined with appreciable accuracy because they evaporate during sample melting (Fig. 9). The results demonstrated that levitation melting was a suitable preparation technique for bulk refractory elements, but not suited for moderately volatile elements like $\mathrm{Na}$ and $\mathrm{K}$. The results on major and minor non-volatile elements support the conclusion by Pack et al. [28], Pack 
Table 2 Chemical composition of the starting materials

\begin{tabular}{|c|c|c|c|c|}
\hline & Picrite (PB-63, XRF*) & Lherzolite GZG1275/1 (XRF**) & Lherzolite GZG1275/1 (EPMA) & Lherzolite + metal oxides (mass balance) \\
\hline $\mathrm{SiO}_{2}$ & 37.5 & 43.4 & 44.3 & 26.47 \\
\hline $\mathrm{TiO}_{2}$ & 0.63 & 0.45 & 0.49 & 0.27 \\
\hline $\mathrm{Al}_{2} \mathrm{O}_{3}$ & 6.10 & 7.2 & 7.3 & 4.40 \\
\hline $\mathrm{MnO}$ & 0.2 & 0.13 & 0.09 & 0.08 \\
\hline $\mathrm{FeO}$ & 13.9 & 7.7 & 7.4 & 39.63 \\
\hline $\mathrm{CoO}$ & 0.02 & n.a. & n.a. & 0.14 \\
\hline $\mathrm{NiO}$ & 0.15 & n.a. & n.a. & 3.95 \\
\hline $\mathrm{MgO}$ & 26.7 & 33.1 & 34.1 & 20.18 \\
\hline $\mathrm{CaO}$ & 4.00 & 5.9 & 6.0 & 3.59 \\
\hline $\mathrm{Na}_{2} \mathrm{O}$ & 0.34 & 0.2 & 0.08 & 0.12 \\
\hline $\mathrm{K}_{2} \mathrm{O}$ & 0.22 & 0.02 & $<0.01$ & 0.01 \\
\hline $\mathrm{P}_{2} \mathrm{O}_{5}$ & 0.06 & 0.01 & $<0.01$ & $<0.01$ \\
\hline $\mathrm{H}_{2} \mathrm{O}^{+}$ & 8.40 & n.a. & n.a. & - \\
\hline $\mathrm{H}_{2} \mathrm{O}^{-}$ & 0.78 & n.a. & n.a. & - \\
\hline Total & 99.0 & 98.1 & 99.8 & - \\
\hline$t_{\text {liquidus }}{ }^{* * *}$ & $1620^{\circ} \mathrm{C}$ & $1655^{\circ} \mathrm{C}$ & $1655^{\circ} \mathrm{C}$ & $1240^{\circ} \mathrm{C}$ \\
\hline
\end{tabular}

Data are given in wt.\% of the oxides.

*all Fe as FeO, **from Schoenberg et al., 2006., ${ }^{* * *}$ MELTS, water-free basis

[29] and Patzer et al. [30] that aerodynamic levitation melting is a suitable method for the preparation of bulk rocks for analyses of refractory elements.

\section{Alkali evaporation experiments}

The test with picrite PB-63 demonstrated that aerodynamic levitation in combination with ICPMS is a promising new technique for the investigation of evaporation from silicate melts. The experiment showed that $\mathrm{Na}$ and $\mathrm{K}$ evaporated in the same relative proportions from the melt. The $\mathrm{Na} / \mathrm{K}$ mass ratio in the evaporated material (0.95 $1.2)$ is similar to the ratio in the picrite PB-63 $(\mathrm{Na} / \mathrm{K}=$ 1.22 , Table 2). This observation was in agreement with the observed evaporative loss of $\mathrm{Na}$ and $\mathrm{K}$ from the USGS rock standards; except for the most silica rich samples (Fig. 9). This suggests that $\mathrm{Na}$ and $\mathrm{K}$ were similarly volatile under experimental conditions (1 bar, Ar-atmosphere). The most $\mathrm{SiO}_{2}$-rich rock samples (GSP-2, RGM-1)

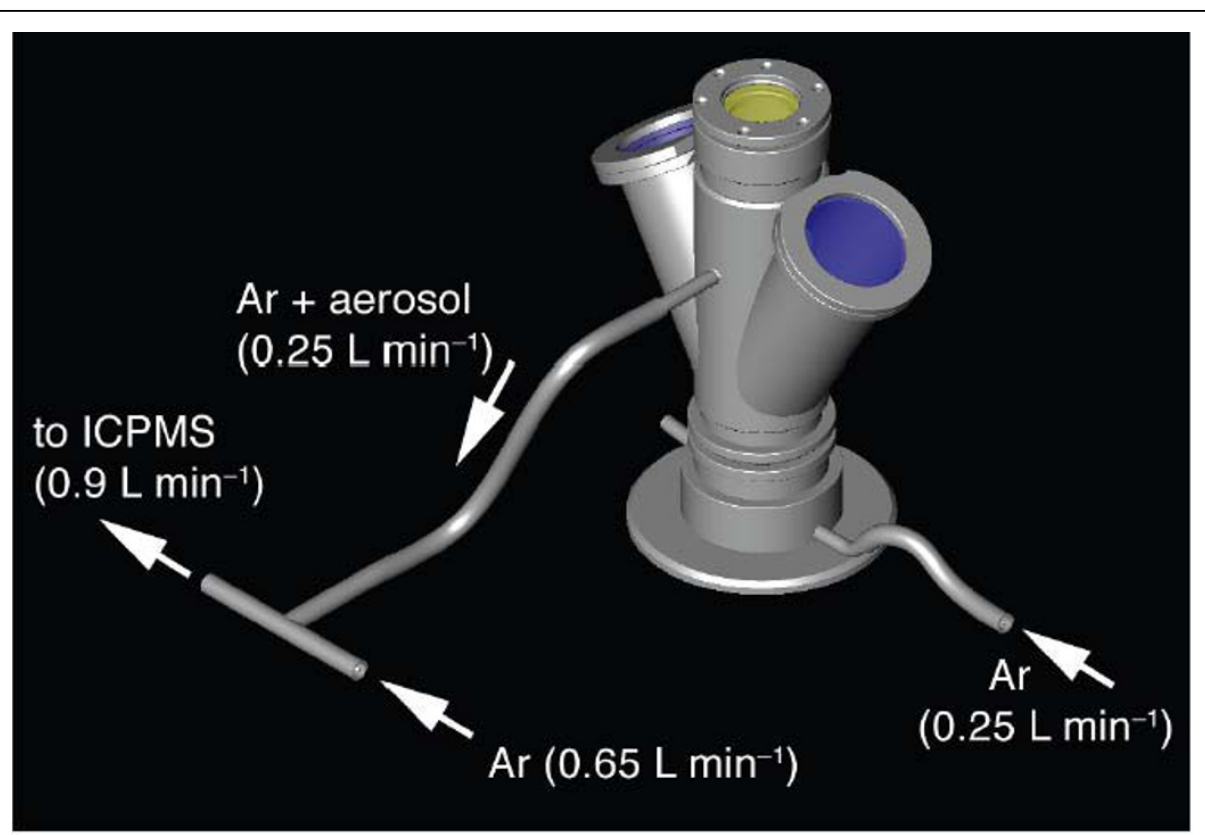

Figure 10 Sketch illustrating the set up for the evaporation experiment. The exhaust of the levitation chamber was connected to the inlet of the ICPMS. Argon was used as levitation gas. 
Table 3 List of the RSF values that were obtained in a period of 8 month for isotopes analyzed in this study

\begin{tabular}{|c|c|c|c|c|c|c|c|}
\hline Date & $\mathrm{RSF}_{24 \mathrm{Mg}}$ & $\mathrm{RSF}_{27 \mathrm{Al}}$ & $\mathrm{RSF}_{29 \mathrm{Si}}$ & $\mathrm{RSF}_{39 \mathrm{~K}}$ & $\mathrm{RSF}_{43 \mathrm{Ca}}$ & $\mathrm{RSF}_{55 \mathrm{Mn}}$ & $\mathrm{RSF}_{57 \mathrm{Fe}}$ \\
\hline August 27, 2009 & 2.32 & 2.34 & 62.82 & 0.73 & 326.92 & 0.33 & 17.63 \\
\hline April 23, 2009 & 1.95 & 1.74 & 62.90 & 1.69 & 299.38 & 0.29 & 13.97 \\
\hline March 1, 2009 & 1.82 & 1.46 & 57.98 & 1.09 & 229.24 & 0.26 & 12.97 \\
\hline December 19, 2008 & 1.53 & 1.39 & 63.37 & 0.46 & 323.38 & 0.28 & 14.21 \\
\hline Average & 1.91 & 1.73 & 61.77 & 0.99 & 294.73 & 0.29 & 14.70 \\
\hline Standarderror & 0.16 & 0.22 & 1.27 & 0.27 & 22.67 & 0.02 & 1.02 \\
\hline
\end{tabular}

The data were obtained by UV-laser ablation ICPMS of NIST 610 reference material.

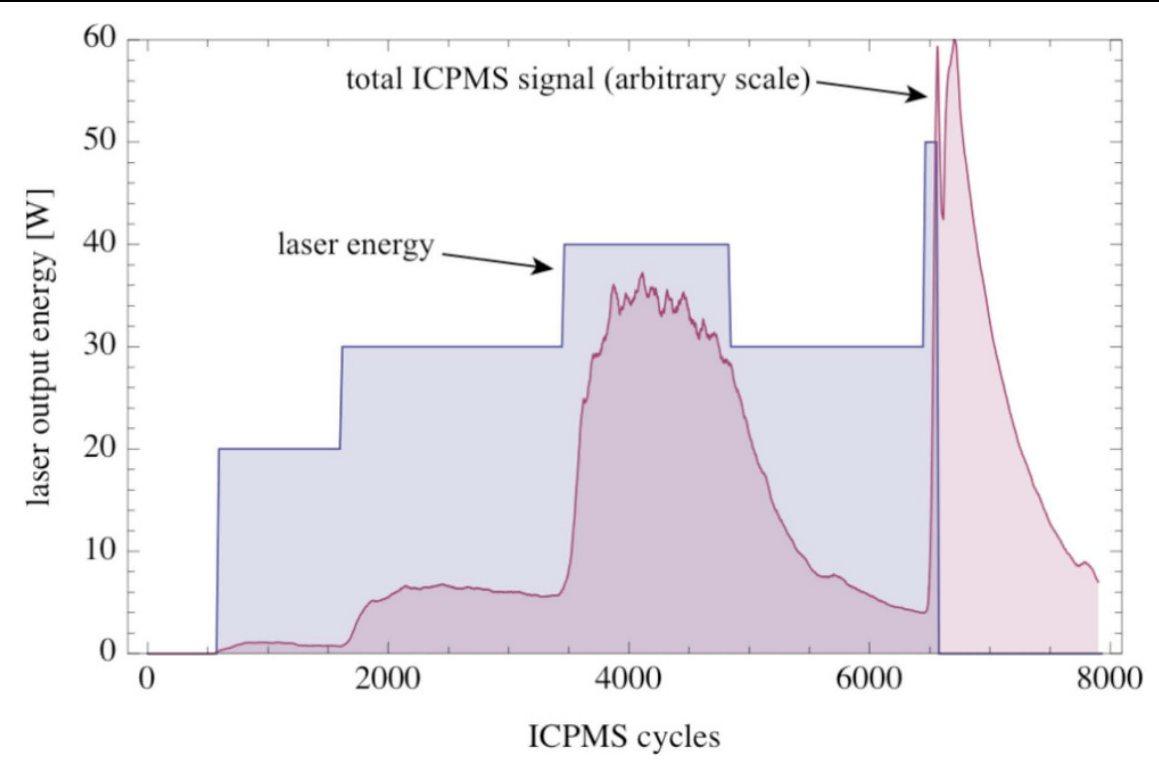

Figure 11 Plot of the laser output energy vs. the number of ICPMS cycles (7.7 $\mathbf{c y c l s ~ s}^{-1}$; blue). The red filled curve shows the normalized total ICPMS signal ( $\mathrm{Na}, \mathrm{Mg}, \mathrm{Al}, \mathrm{Si}, \mathrm{K}, \mathrm{Ca}, \mathrm{Mn}$ and Fe; arbitrary scale). The total ICPMS signal was smoothed with a moving average of 20 cycles.

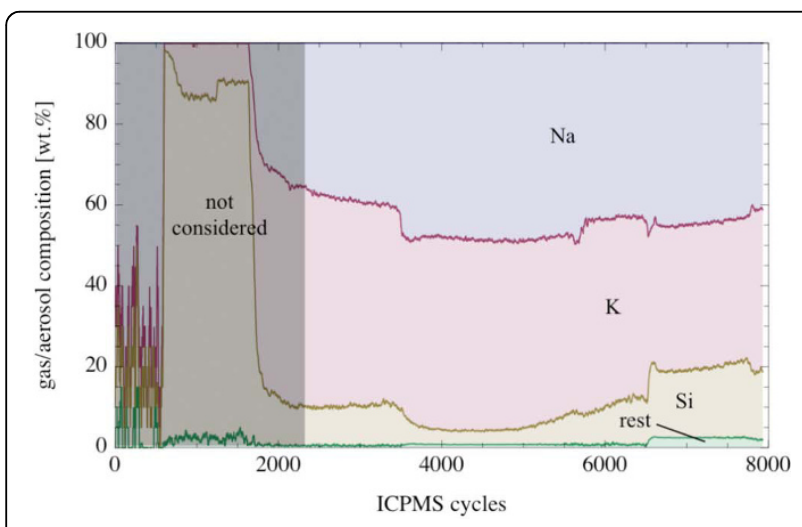

Figure 12 Plot of the composition of the evaporated gas/ aerosol from picrite PB-63 vs. number of cycles $\left(7.7 \mathrm{cycl} \mathrm{s}^{-1}\right)$.

The signals were smoothed with a moving average of 20 cycles.

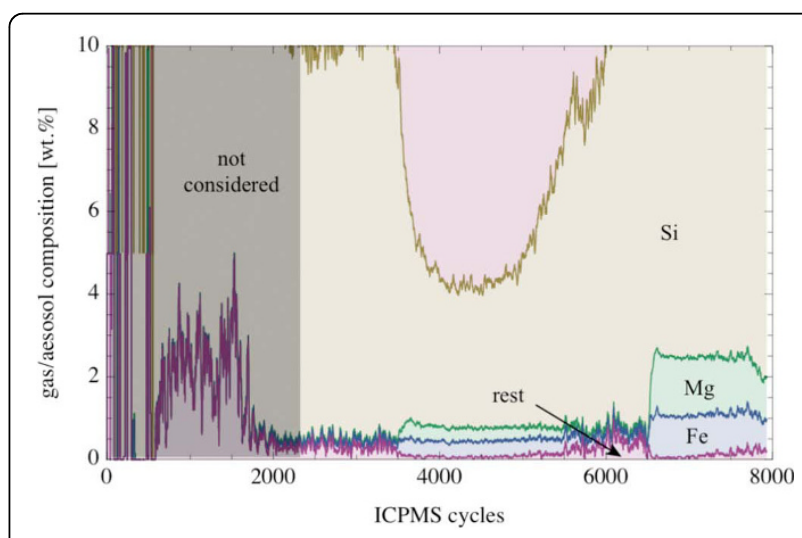

Figure 13 Plot of the composition of the evaporated material from picrite PB-63 (enlarged part of Fig. 12). Minor components in the evaporated phase are $\mathrm{Mg}$ and Fe $(\sim 1 \mathrm{wt} . \%$ of the oxide, respectively) with the remaining elements $\mathrm{Al}, \mathrm{Ca}$ and $\mathrm{Mn}$ amounting $<0.5 \mathrm{wt} . \%$. The signals were smoothed with a moving average of 20 cycles. 
Table 4 Result of EPMA measurements of silicate and metal of the reduced chondrite NWA 869

\begin{tabular}{lrr}
\hline Sample & NWA 869 (silicate) & NWA 869 (metal) \\
\hline $\mathrm{SiO}_{2}$ & 40.0 & - \\
$\mathrm{TiO}_{2}$ & 0.14 & - \\
$\mathrm{Al}_{2} \mathrm{O}_{3}$ & 2.9 & - \\
$\mathrm{MnO}$ & 0.37 & - \\
$\mathrm{FeO}$ & 27.0 & - \\
$\mathrm{MgO}$ & 26.5 & - \\
$\mathrm{CaO}$ & 2.72 & - \\
$\mathrm{Na}_{2} \mathrm{O}$ & 0.09 & - \\
$\mathrm{K}_{2} \mathrm{O}$ & $<.05$ & - \\
$\mathrm{P}_{2} \mathrm{O}_{5}$ & 0.037 & - \\
$\mathrm{Cr}_{2} \mathrm{O}_{3}$ & 0.59 & - \\
$\mathrm{NiO}$ & 0.15 & 53.1 \\
$\mathrm{Fe}$ & - & 1.1 \\
$\mathrm{Co}$ & - & 45.0 \\
$\mathrm{Ni}$ & - & 99.2 \\
$\mathrm{Total}$ & 100.4 & \\
\hline $\mathrm{Da}$ & &
\end{tabular}

showed a preferred evaporation of Na relative to K (Fig. 9). The difference is likely related to a higher ratio of the alkali oxide activity coefficients $\gamma_{\mathrm{Na}_{2} \mathrm{O}} / \gamma_{\mathrm{K}_{2} \mathrm{O}}$ of felsic melts relative to mafic melts. An increase in $\gamma$ leads to an increase in vapor pressure and hence elevated evaporation rates.
Figure 14 Photography of the reduced Iherzolite-metal oxide mixture. Metal exsolved from the silicate. The diameter of the sphere was $\sim 2 \mathrm{~mm}$. The material was levitated with a mixture of 98 vol.\% $\mathrm{Ar}$ and 2 vol.\% $\mathrm{H}_{2}$.
Data are reported in wt.\% of the oxides (silicate) or elements (metal).

The response time to changes in laser energy were in the range of tens of seconds and allowed studies of evaporation processes with high time-resolution. Chondrules formed within a few minutes [34] in the solar nebula.

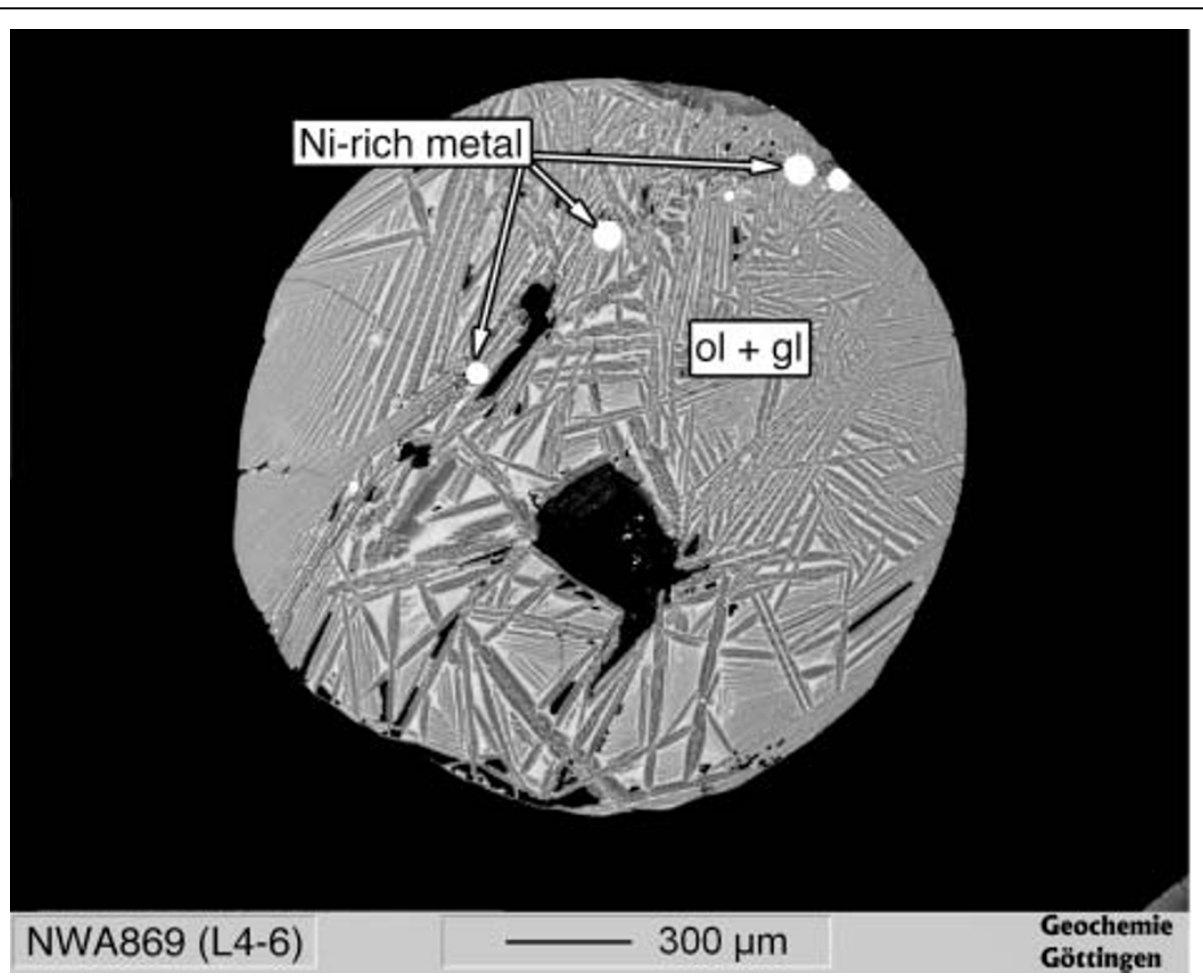

Figure 15 Back scattered electron image of NWA 869 L4-6 ordinary chondrite. The sample was entirely oxidized prior to levitation melting A 98 vol.\% $\mathrm{Ar}+2$ vol.\% $\mathrm{H}_{2}$ mixture was used as levitating gas. 
Therefore, aerodynamic levitation in combination with ICPMS is a suitable technique to monitor evaporation of alkalis under different conditions (melt composition, atmosphere, temperatures). A smaller sample chamber may reduce the response times.

\section{Reduction experiments}

The test with the lherzolite-oxide mixture demonstrated that siderophile elements could be extracted from silicate by means of levitation melting in reducing atmosphere. Siderophile trace elements can be extracted along with Fe and Ni by sample reduction. We demonstrated (Fig. 14) that levitation in an $\mathrm{Ar}-\mathrm{H}_{2}$ mixture allows reduction of a major fraction of $\mathrm{Fe}$ and $\mathrm{Ni}$ to metal. Highly siderophile elements (e.g., platinum group elements) are expected to be quantitatively concentrated in the metal. Laser ablation ICPMS analyses of siderophile trace elements have been successfully conducted on iron meteorites $[44,45]$.

The reduction experiment with the oxidized chondrite material showed that reduction of oxides $\left(\mathrm{FeO}, \mathrm{Fe}_{2} \mathrm{O}_{3}\right.$, $\mathrm{NiO})$ to metal alloys occurred within $30 \mathrm{~s}$. The high $\mathrm{Ni}$ concentration in the resultant metal was due to the low degree of reduction. Nickel is more siderophile than Co, which is more siderophile than Fe. It follows from the difference in redox potential that $\mathrm{Ni}$ is reduced first, followed by Co. The superchondritic $\mathrm{Ni} / \mathrm{Fe}(0.85)$ and $\mathrm{Co} / \mathrm{Fe}$ ratios $(0.021)$ in the metal in the run product are clearly the result of the preferential reduction of $\mathrm{Ni}$ and $\mathrm{Co}$. The chondritic ratios are $0.058(\mathrm{Ni} / \mathrm{Fe})$ and $0.0028(\mathrm{Co} / \mathrm{Fe})$ [39]. The Fe/Si ratio of the silicate is only little below the L-chondritic ratio. This demonstrates that most Fe remained in the silicate. The low $\mathrm{Ni} / \mathrm{Fe}$ ratio in the silicate is evidence that most $\mathrm{Ni}$ was reduced to metal.

Chondrule formation took place in a more reduced environment of the solar nebula, which was essentially $\mathrm{H}_{2}$, and chondrule melting lasted over the range of minutes to tens of minutes. It is therefore plausible that metal in chondrites has formed by reduction during the brief chondrule melting event [36].

\section{Conclusions}

Aerodynamic levitation in combination with microchemcial methods (EPMA, LA-ICPMS) is an efficient means of bulk rock preparation for analyses of nonvolatile major, minor and trace elements. The strength of the technique lies in the absence of contamination and the option to analyze only small $(\sim 10 \mathrm{mg})$ samples. A further advantage is that no flux is used, which would dilute the elements of interest and could cause contamination, namely for trace and ultra trace elements. A disadvantage of the sample preparation technique involving containerless fusion is evaporative loss of moderately volatile elements like $\mathrm{Na}$ and $\mathrm{K}$.
Aerodynamic levitation in combination with ICPMS online monitoring of the evaporated material allows time-resolved studies of the evaporation behavior at high temperatures. It is demonstrated that $\mathrm{Na}$ and $\mathrm{K}$ are similarly volatile at 1 bar Ar atmosphere. This observation is confirmed by results from fused rock standards.

Levitation and melting experiments in reduced atmosphere demonstrated that metal and silicate could be separated by reduction. The exsolution of metal did not affect the stability of the levitated melt. The experiment with an oxidized chondrite showed that Ni-rich metal is exsolved within $\sim 30 \mathrm{~s}$ of melting.

\section{Acknowledgements}

A. Thomen (Nancy, France) is thanked for his assistance in early stages of the development of the levitation apparatus. The work of G. Tondock, who built the levitation apparatus (nozzle, sample chamber) is appreciated. A. Kropf wrote a helpful LABVIEW program that allowed graphical control of the gas flow. Y. Xiao is thanked for providing the rock standards. Corrections by $A$. Patzer improved the English.

Constructive comments by the $\mathrm{AE}$ and an anonymous reviewer helped to improve the manuscript.

\section{Authors' contributions}

AP designed the levitation device and conducted first experiments. AP wrote the manuscript. KK and AK conducted the EPMA analyses. NA prepared the USGS samples. KS, NA and AP conducted the evaporation experiments and ICPMS analyses of the evaporated materials. All authors have read and approved the final manuscript.

\section{Competing interests}

The authors declare that they have no competing interests.

Received: 6 October 2009 Accepted: 27 September 2010 Published: 27 September 2010

References

1. Sandhage $\mathrm{KH}$, Yurek GJ: Indirect dissolution of sapphire into silicate melts. Journal of the American Ceramic Society 1988, 71:478-489.

2. Malvin DJ: Silica-glass containers for high-temperature experiments. American Mineralogist 1988, 73:1198-1200.

3. Grove $\mathrm{T}$ : Use of FePt alloys to eliminate the iron loss problem in 1 atmosphere gas mixing experiments: Theoretical and practical considerations. Contributions to Mineralogy and Petrology 1982, 78:298-304.

4. Johannes W, Bode B: Loss of iron to the Pt-container in melting experiments with basalts and a method to reduce it. Contributions to Mineralogy and Petrology 1978, 67:221-225

5. Nordine PC, Atkins RM: Aerodynamic levitation of laser-heated solids in gas jets. Review of Scientific Instruments 1982, 53:1456-1464.

6. Oran WA, Berge LH: Containerless melting and solidificating of materials with an aerodynamic levitation system. Review of Scientific Instruments 1982, 53:851-853.

7. Ouaida MB, Badie JM: Dispositif de levitation aérodynamique associe à un concentrateur solaire pour l'étude de materiaux liquides. Journal of Physics (Series E: Scientific Instrumentation) 1982, 15:941-944.

8. Landron C, Hennet L, Thiaudiere D, Price DL, Greaves GN: Structure of liquid oxides at very high temperatures. Nuclear Instruments and Methods in Physics Research 2003, B 199:481-488.

9. Weber JKR, Benmore C, Tangeman JA, Siewenie J, Heira KJ: Structure of binary $\mathrm{CaO}-\mathrm{Al}_{2} \mathrm{O}_{3}$ and $\mathrm{SrO}-\mathrm{Al}_{2} \mathrm{O}_{3}$ liquids by combined levitation-neutron diffraction. The Journal of Neutron Research 2002, 11:113-121.

10. Glorieux B, Millot F, Rifflet J-C: Surface tension of liquid alumina from contactless techniques. International Journal of Thermophysics 2002, 23:1249-1257. 
11. Glorieux B, Millot F, Rifflet J-C, Coutures J-P: Density of superheated and undercooled liquid alumina by a conactless method. International Journal of Thermophysics 1999, 20:1085-1094.

12. Landron C, Hennet $L$, Thiaudiere D: Combining measurements of synchrotron radiation and neutrons from liquids at high temperature. Analytical Sciences 2001, 17:165-168.

13. Nordine PC, Weber JKR, Abadie JG: Properties of high-temperature melts using levitation. Pure and Applied Chemistry 2000, 72:2127-2136.

14. Arai $Y$, Aoyama $T$, Yoda S: Spherical sapphire single-crystal synthesis by aerodynamic levitation with high growth rate. Review of Scientific Instruments 2004, 75:2262-2265.

15. Blander $M$, Pelton $A D$, Jung $H-H$, Weber R: Non-equilibrium concepts lead to a unified explanation of the formation of chondrules and chondrites. Meteoritics and Planetary Science 2004, 39:1897-1910.

16. Nagashima K, Moriuchi Y, Tsukamoto K, Tanaka K, Kobatake H: Critical cooling rates for glass formation in levitated $\mathrm{Mg}_{2} \mathrm{SiO}_{4}-\mathrm{MgSiO}_{3}$ chondrule melts. Journal of Mineralogical and Petrological Sciences 2008, 103:204-208.

17. Nagashima K, Tsukamoto K, Satoh H, Kobatake H, Dold P: Reproduction of chondrules from levitated, hypercooled melts. Journal of Crystal Growth 2006, 293:193-197.

18. Weber JKR, Tangeman JA, Key TS, Heira KJ, Paradis P-F, Ishikawa T, Yu J, Yoda S: Novel synthesis of calcium oxide-aluminum oxide glasses. Japanese Journal of Applied Physica 2002, 41:3029-3030.

19. Tangeman JA, Phillips BL, Navrotsky A, Weber JKR, Hixson AD, Key TS: Vitreous forsterite $\left(\mathrm{Mg}_{2} \mathrm{SiO}_{4}\right)$ : synthesis, structure and thermochemistry. Geophysical Research Letters 2001, 28:2517-2521.

20. Skinner $L B$, Barnes $A C$, Crichton $W$ : Novel behaviour and structure of new glasses of the type Ba-Al-O and Ba-Al-Ti-O produced by aerodynamic levitation and laser heating. Journal of Physics: Condensed Matter 2006, 18 : L407.

21. Albarède F: Geochemistry: an introduction Cambridge University Press, 2 2003.

22. Eggins S: Laser ablation ICP-MS analysis of geological materials prepared as lithium borate glasses. Geostandards and Geoanalytical Research 2003, 27:147-162.

23. Nehring F, Jacob D, Barth M, Foley S: Laser-ablation ICP-MS analysis of siliceous rock glasses fused on an iridium strip heater using $\mathrm{MgO}$ dilution. Microchimica Acta 2008, 160:153-163.

24. Stoll B, Jochum KP, Herwig K, Amini M, Flanz M, Kreuzburg B, Kuzmin D, Willibold M, Enzeweiler J: An automated iridium-strip heater for LA-ICPMS bulk analysis of geological samples. Geostandards and Geoanalytical Research 2007, 32:5-26.

25. Yu Z, Norman M, Robinson P: Major and trace element analysis of silicate rocks by XRF and laser ablation ICP-MS using lithium borate fused glasses: matrix effects, instrument response and results for international reference materials. Geostandards and Geoanalytical Research 2003, 27:67-89.

26. Sylvester PJ: Trends in analytical developments and earth science applications in LA-ICP-MS and LA-MC-ICP-MS for 2004 and 2005. Geostandards and Geoanalytical Research 2006, 30:197-207.

27. Jochum KP, Stoll B, Herwig K, Willbold M, Hofmann AW, Amini M, Aarburg S, Abouchami W, Hellebrand E, Mocek B, et al: MPI-DING reference glasses for in-situ microanalysis: new reference values for element concentrations and isotope ratios. Geochemistry Geophysics Geosystems 2006, 7:Q02008.

28. Kropf A, Pack A: Primordial alkalis in chondrules. Geochimica et Cosmochimica Acta 2007, 71:A526.

29. Pack A: Fractionation of refractory lithophile elements in bulk chondrites and chondrite components. Lunar and Planetary Science Conference 2008.

30. Patzer A, Pack A, Gerdes A: Zirconium and hafnium in meteorites. Meteoritics and Planetary Science 2010.

31. Palme $\mathrm{H}$ : Chemical and isotopic heterogeneity in protosolar matter. Philosophical Transactions of the Royal Society A: Mathematical, Physical and Engineering Sciences 2001, 359:2061-2075.

32. Alexander C, Grossman JN, Ebel DS, Ciesla FJ: The formation conditions of chondrules and chondrites. Science 2008, 320:1617-1619.

33. Borisov A, Pack A, Kropf A, Palme H: Partitioning of Na between olivine and melt: An experimental study with application to the formation of meteoritic $\mathrm{Na}_{2} \mathrm{O}$-rich chondrule glass and refractory forsterite grains. Geochimica et Cosmochimica Acta 2008, 72:5558-5573.

34. Zanda B: Chondrules. Earth and Planetary Science Letters 2004, 224:1-17.
35. Galy A, Young ED, Ash RD, Keith O'Nions R: The formation of chondrules at high gas pressures in the Solar Nebula. Science 2000, 290:1751-1753.

36. Connolly HC, Huss GR, Wasserburg GJ: On the formation of Fe-Ni metal in Renazzo-like carbonaceous chondrites. Geochimica et Cosmochimica Acta 2001, 65:4567-4588.

37. Pack A, Yurimoto $H$, Palme $H$ : Petrographic and oxygen-isotope study of refractory forsterites from R-chondrite Dar al Gani 013 (R3.5-6), unequilibrated ordinary and carbonaceous chondrites. Geochimica et Cosmochimica Acta 2004, 68:1135-1157.

38. Jochum KP, Nohl U, Herwig K, Lammel E, Stoll B, Hoffmann AE: GeoReM: a new geochemical database for reference materials and isotopic standards. Geostandards and Geoanalytical Research 2005, 29:333-338.

39. Lodders K: Solar system abundances and condensation temperatures of the elements. The Astrophysical Journal 2003, 591:1220-1247.

40. Schoenberg R, von Blanckenburg F: Modes of planetary-scale Fe fractionation. Earth and Planetary Science Letters 2006, 252:342-359.

41. Ghiorso MS, Sack RO: Chemical mass transfer in magmatic processes. IV. A revised and internally consistent thermodynamic model for the interpolation and extrapolation of liquid-solid equilibria in magmatic systems at elevated temperatures and pressures. Contributions to Mineralogy and Petrology 1995, 119:197-212.

42. Asimov PD, Ghiorso MS: Algorithmic modifications extending MELTS to calculate subsolidus phase relations. American Mineralogist 1998, 83:1127-1131.

43. Conolly HC, Zipfel J, Grossman JN, Folco L, Smith C, Jones RH, Righter K, Zolensky M, Russell SS, Bendix GK, et al: The meteoritical bulletin, No. 90, 2006 September. Meteoritics and Planetary Science 2006, 41:1383-1418.

44. Campbell AC, Humayun M: Trace element microanalysis in iron meteorites by laser ablation ICPMS. Analytical Chemistry 1999, 71:939-946.

45. Mullane E, Alard O, Gounelle M, Russell SS: Laser ablation ICP-MS study of IIIAB irons and pallasites: constraints on the behaviour of highly siderophile elements during and after planetesimal core formation. Chemical Geology 2004, 208:5-28.

doi:10.1186/1467-4866-11-4

Cite this article as: Pack et al:: Description of an aerodynamic levitation apparatus with applications in Earth sciences. Geochemical Transactions 2010 11:4.

\section{Submit your next manuscript to BioMed Central and take full advantage of:}

- Convenient online submission

- Thorough peer review

- No space constraints or color figure charges

- Immediate publication on acceptance

- Inclusion in PubMed, CAS, Scopus and Google Scholar

- Research which is freely available for redistribution

Submit your manuscript at www.biomedcentral.com/submit
C Biomed Central 